Portland State University

PDXScholar

\title{
Gratitude Reception and Physical Health: Examining the Mediating Role of Satisfaction with Patient Care in a Sample of Acute Care Nurses
}

\author{
Alicia R. Starkey \\ Portland State University \\ Cynthia D. Mohr \\ Portland State University, cynthia.mohr@pdx.edu \\ David M. Cadiz \\ Portland State University, dcadiz@pdx.edu \\ Robert R. Sinclair \\ Clemson University
}

Follow this and additional works at: https://pdxscholar.library.pdx.edu/psy_fac

Part of the Psychology Commons

Let us know how access to this document benefits you.

\section{Citation Details}

Starkey, A. R., Mohr, C. D., Cadiz, D. M., \& Sinclair, R. R. (2019). Gratitude reception and physical health: Examining the mediating role of satisfaction with patient care in a sample of acute care nurses. The Journal of Positive Psychology, 1-10.

This Post-Print is brought to you for free and open access. It has been accepted for inclusion in Psychology Faculty Publications and Presentations by an authorized administrator of PDXScholar. Please contact us if we can make this document more accessible: pdxscholar@pdx.edu. 


\title{
Gratitude reception and physical health: Examining the mediating role of satisfaction with patient care in a sample of acute care nurses
}

\author{
Alicia R. Starkey ${ }^{a *}$, Cynthia D. Mohr ${ }^{\mathrm{a}}$, David M. Cadiz ${ }^{\mathrm{b}}$, and Robert R. Sinclair ${ }^{\mathrm{c}}$ \\ ${ }^{a}$ Department of Psychology, Portland State University, Portland, USA **; ${ }^{\text {DDepartment of }}$ \\ Management, Portland State University, Portland, USA; 'Department of Psychology, Clemson \\ University, Clemson, USA
}

Alicia R. Starkey, M.S.*; Address: P.O. Box 751, Portland, OR 97207-0751; Phone: (503) 725-

3923; Email: astarkey@pdx.edu

Cynthia D. Mohr, Ph.D.; Address: P.O. Box 751, Portland, OR 97207-0751; Phone: (503) 725-

3923; Email: $\underline{\text { cdmohr@pdx.edu }}$

David M. Cadiz, Ph.D.; Address: P.O. Box 751, Portland, OR 97207-0751; Phone: (503) 725-

9926; Email: $\underline{\text { dcadiz@pdx.edu }}$

Robert R. Sinclair, Ph.D.; Address: 418 Brackett Hall, Clemson, SC 29634; Phone: (864) 656-

3931; Email: rsincla@clemson.edu

*Corresponding author

**Research conducted at PSU

Citation:

Starkey, A. R., Mohr, C. D., Cadiz, D. M., \& Sinclair, R.R. (2019). Gratitude reception and physical health: Examining the mediating role of satisfaction with patient care in a sample of acute care nurses. The Journal of Positive Psychology, 1-10.

DOI: 10.1080/17439760.2019.1579353 


\begin{abstract}
Literature examining well-being benefits of gratitude experiences is currently thriving in psychological science. However, evidence of the physical health benefits of gratitude remains limited. Research and theory in affective science suggests an indirect relationship between gratitude and physical health. This study examines how receiving expressions of gratitude predicts physical health outcomes in a sample of acute care nurses over time. Registered nurses $(N=146)$ practicing in Oregon completed weekly surveys over 12 consecutive weeks describing their positive and negative events, health, and work-related experiences. Multilevel mediation models revealed that being thanked more often at work was positively related to a nurse's satisfaction with the care they provided within that week, which subsequently predicted sleep quality, sleep adequacy, headaches, and attempts to eat healthy. These findings contribute to literature demonstrating the health benefits of gratitude by indicating that benefactors may experience improvements in subjective physical health through positive domain-relative satisfaction.
\end{abstract}

Keywords: gratitude; emotion expression; physical health; well-being; nursing; positive psychology 


\section{Introduction}

Gratitude has been studied as a personality trait, emotional state, and moral value, among other conceptualizations (Emmons, McCullough, \& Tsang, 2003). When conceptualized as an emotion, gratitude signals that a person has benefited or received a positive outcome from an external source (Emmons \& McCullough, 2003). Thus, gratitude is a positive affective experience that typically follows another's beneficial and caring gesture towards the self, particularly when the gesture is perceived to be costly or valuable, intentional, and voluntary (McCullough, Kimeldorf \& Cohen, 2008). Consequently, gratitude is distinct from other positive emotions such as optimism or happiness (Wood et al., 2010). This other-focused, interpersonalemotional definition is what Lambert, Graham, and Fincham (2009), termed "benefit-triggered gratitude" and is of particular interest in this study, as opposed to "generalized gratitude" (e.g., an individual's broad state of thankfulness or trait gratitude). Viewing gratitude within an interpersonal framework, not only is the experience of gratitude important, but the expression of gratitude becomes critical to understanding state gratitude's link to well-being.

Expressed gratitude holds positive outcomes for both the expresser and benefactor. For example, expressed gratitude is related to increased life satisfaction and well-being over time for the expresser of gratitude (Lyubomirsky, Dickerhoof, Boehm, \& Sheldon, 2011). While the majority of literature examining gratitude has focused on the expresser (i.e., the person who benefits and then expresses their gratitude toward a benefactor), more recent work has examined the impact of gratitude for those receiving expressions of gratitude (i.e., the benefactor). For example, Grant and Gino (2010) found being the target of gratitude from strangers strengthens one's sense of social worth and spurs additional helping behaviors. In close relationships, when caregivers receive thanks from their romantic partner, they view their partner as more caring, 
understanding, and validating which predicts later positive psychological outcomes (Algoe, Kurtz, \& Hillaire, 2016). Extant research documents the psychological and social well-being outcomes related to receiving gratitude expressions, yet few studies have examined gratitude reception and physical health outcomes. Researchers suggest that affect such as gratitude shares an indirect relationship with physical health (DeSteno, Gross, \& Kubzansky, 2013). Extending this literature, the current study targets one personal well-being resource, satisfaction, as a mechanism through which gratitude expressions predict physical health.

\section{Indirect relation of gratitude and physical health}

Positive emotions, including gratitude, are theorized to build a variety of social and psychological resources (Fredrickson, 2004). Recent work hypothesizes that expressions of gratitude not only have social benefits that help build high quality relationships, but also predict increased psychological resources (Algoe, 2012). Algoe and Zhaoyang (2016) found that expressed gratitude predicted psychological well-being outcomes in a daily study, including increased life satisfaction, resilience, positive emotions and decreased negative emotions. Further, the explicit expression of gratitude may strengthen these benefits over time (Algoe \& Stanton, 2012). For example, benefactors who received a gratitude expression from their partner showed increased relationship satisfaction up to 6 months later (Algoe, Fredrickson, \& Gable, 2013), indicating that benefactors may experience lasting effects of gratitude expressions. Based on these findings, we expect that expressions of gratitude will support increases in psychological resources that will, in turn, spillover to benefit physical health.

While evidence linking gratitude expression and physical health is limited, literature examining 'generalized gratitude' (including trait gratitude; Lambert, Graham, et al., 2009) has focused attention on the links between gratitude, well-being, and physical health outcomes. In 
their seminal work, Emmons and McCullough (2003) found a direct relationship between gratitude and health such that people who were induced to feel more grateful showed reduced illness symptoms and increased hours of exercise. Further, evidence suggests that generalized gratitude predicts better subjective psychological well-being, physical health, and healthy behavior, such as the propensity to exercise and eat healthy (Hill, Allemand, \& Roberts, 2013). People who are more grateful or induced to feel more gratitude have fewer negative physical symptoms (e.g., pain), exhibit healthier behaviors (e.g., eating nutritious foods), show better physiological outcomes such as blood pressure (Jackowska, Brown, Ronaldson, \& Steptoe, 2015), and report increased sleep quality (Wood, Joseph, Lloyd, \& Atkins, 2009).

In addition to a direct relationship, research on generalized gratitude has begun to identify psychological mechanisms linking gratitude and health. For example, people who are more grateful report reduced loneliness and, in turn, better physical health (O'Connell, O’Shea, \& Gallagher, 2016). Further, Wood and colleagues (2009) found that positive cognitions, such as relishing recently experienced positive events, before bed mediated the relationship between generalized gratitude and better sleep. In turn, psychological mechanisms may be particularly important for the interpretation and benefit of gratitude expressions. For example, researchers argue that gratitude does not operate purely behaviorally (e.g., through interpersonal expression) but rather, an individual must interpret the expression through a positive lens (Wood et al., 2010). People must be oriented towards the positive in life in order to reap the benefits of gratitude. This work suggests that orienting oneself to the positive aspects about one's present state, such as feeling satisfied, may be one mechanism of gratitude. For example, Lambert, Fincham, Stillman, and Dean (2009) found that satisfaction with life mediated the relationship between trait gratitude and decreased materialism (i.e. striving to increase personal possessions). 
Taken together, previous research on both generalized gratitude and other-focused expressions of gratitude show that gratitude relates to increased psychological well-being resources. Literature on generalized gratitude suggests that increased psychological well-being resources, predicted by gratitude, is associated with positive physical health outcomes. Drawing on generalized and other-focused gratitude research, this study addresses a gap in literature related to the physical health and intrapersonal benefits of expressed gratitude by examining how receiving gratitude expressions predicts nurses' physical well-being via work-related satisfaction.

\section{Gratitude, satisfaction, and physical health in the context of nursing}

Nursing is a helping profession comprising the largest group of health-care professionals in the U.S. (U.S. Department of Labor, 2018). Nurses are central to the delivery of health-care services in a system facing increased pressures including aging populations, and greater expectations regarding quality of care (Aiken et al., 2012). Nurses engage in many work behaviors which may evoke gratitude from coworkers, supervisors, patients, and patients' families- from simply completing tasks efficiently and empathetically to helping an overloaded colleague. Given that people spend a significant portion of their lives at work, satisfaction with one's work should have a significant impact on one's physical health. Moreover, nurses, in particular, view being in the nursing profession as a part of their personal identity and calling (Eley, Eley, Bertello, \& Rogers-Clark, 2012). However, nursing work is demanding and nurses may be more susceptible to adverse physical health outcomes.

Indeed, nurses' job demands are linked to poor sleep (Hasson \& Gustavson, 2010; Winwood \& Lushington, 2006), psychosomatic symptoms such as headaches (Lin, Huang, \& Wu, 2007), and poor nutrition (Tucker, Harris, Pipe, \& Stevens, 2010). Nurses’ poor physical health (e.g., poor sleep quality) is related to fatigue, resulting in greater risk of mistakes and 
patient safety concerns (Lockley et al., 2007). Furthermore, nurses describe feeling unsupported and underappreciated at work (Morrison \& Korol, 2014). This lack of appreciation for healthcare providers can subsequently predict sleep problems and poor self-perceived physical health (Meier, Tschudi, Meier, Dvorak \& Zeller, 2015). Broadly, this research suggests that increased expression of gratitude towards nurses may help alleviate associated adverse physical health symptoms.

Recent evidence suggests gratitude expressed towards nurses may promote well-being outcomes. Nurses who received gratitude expressions from patients had lower symptoms of emotional exhaustion, depersonalization, and increased feelings of personal accomplishment (Converso, Loera, Viotti \& Martini, 2015). Further, supportive positive events that nurses may encounter, including received expressions of gratitude from colleagues and physicians, predict positive work outcomes such as engagement (Sinclair, et al., 2015). Relatedly, nurses' perceived appreciation by their organization predicts higher work-related satisfaction (Adriaenssens, De Gucht, Van Der Doef, \& Maes, 2011). Based on this evidence, we expect that work-related satisfaction may be one mechanism through which received gratitude expressions at work relate to physical health.

Well-established theoretical perspectives regarding positive emotions and work-related resources provide support for these claims. Conservation of Resources theory (COR; Hobfoll, 1989) has received considerable attention as an explanatory mechanism for how work demands affect occupational health (Hobfoll, 2001). COR theory proposes that people strive to retain, protect, and build resources, while aiming to avoid potential or actual loss of these valued resources (Hobfoll, 1989). COR theory can be applied in the context of received gratitude because, similar to social support, receiving thanks can facilitate gains in psychological resources 
such as positive self-image (Hobfoll, 1989). For example, nurses who received gratitude expressions may recover resources that have been lost over the course of a demanding work week. Thus, gratitude expressions received by nurses likely generate work-related psychosocial resources that support their physical health.

Positive emotions serve a restorative function and provide opportunities for growth. Specifically, positive experiences help build resources and broaden one's approach to future experiences (Fredrickson, 2001). Thus, receiving expressions of gratitude may increase psychological well-being such as satisfaction with one's care of others and in turn, better physical health. Recent evidence suggests that satisfaction with work and perceptions of quality care are worldwide concerns in the field of nursing (Aiken et al., 2012; You et al., 2013). However, positive interactions with patients, families, and co-workers may improve nurses' quality of work life. For example, nurses describe that when they provide high-quality care, they have stronger connections with their patients, and are more satisfied with their work (Perry, 2005). In addition, to previously mentioned evidence specific to satisfaction and health reported by nurses, a meta-analysis by Faragher, Cass, and Cooper (2005) found a small-to-medium association between job satisfaction and self-reported physical health indicating that feeling satisfied at work may contribute to one's physical health outcomes. Taken together, this evidence supports that nurses' satisfaction with their care of patients may be one mechanism through which positive emotions such as gratitude predict physical health.

\section{The present study}

This study extends literature examining the relationship between gratitude and physical health by investigating health benefits of receiving gratitude expressions. We examine gratitude reception in the context of nursing, a helping profession associated with demanding work and 
reduced physical health. We address how receiving gratitude at work predicts physical symptoms and health behaviors through nurses' satisfaction with patient care. In addition, we examine this process over time: testing mediation patterns both within-person and between-persons. See Figure 1 for the proposed model based on Preacher, Zhang, and Zyphur (2011). We hypothesize that gratitude reception will predict increased satisfaction with patient care within-person (path $a_{i j}$ ) and between persons (path $a_{j}$ ). In turn, we predict that increased satisfaction with care will be associated with increased subjective physical health outcomes within-person (path $b_{\mathrm{ij}}$ ) and between persons (path $b_{j}$ ). Further, this relationship will remain controlling for gratitude reception across (path $\mathrm{c}_{\mathrm{j}}$ ) and within nurses (path $\mathrm{c}_{\mathrm{ij}}$ ) over time.

[Include Figure 1 near here]

\section{Methods}

\section{Overview}

Data for this study were drawn from the Oregon Nurse Retention Project (ONRP) examining nurses' work-related experiences, occupational health, and retention. The research team collaborated with a nurse's professional organization to recruit acute care nurses working in urban, suburban, and rural areas in Oregon. ONRP consisted of 3 waves of surveys, with an optin weekly survey taking place over 12 weeks in between Waves 1 and 2 . The current analyses focuses on the weekly survey component of the project. For more information about ONRP, see Sinclair and colleagues (2009; Sinclair et al., 2015).

\section{Participants}

Of the 428 acute-care nurses who were recruited for the first wave, 146 nurses opted to participate in the weekly survey. The majority were female (91.1\% female), White (89.7\%), and 
on average 44 years old $(S D=10.71)$. Most of the participating nurses were married $(68.5 \%)$. About half received their bachelors in nursing (48.6\%; $14 \%$ other bachelors), $26 \%$ received an associate degree in nursing, and 6\% received a graduate degree. Nurses in this sample worked mostly full-time (63\%), 31.5\% worked part-time, and had been a nurse for about 17 years on average $(S D=11.9)$.

\section{Procedure}

On Sunday, each week for 12 weeks, participants were provided a link to a web-based survey via email that took approximately 20 minutes to complete. Participants were given a 48hour time window to finish the survey, and were sent a reminder email if they missed two or more consecutive weeks. Participants received \$5 for each survey completed. Nurses' identifying information was removed after survey collection and stored separately from survey responses. Participation in this study was voluntary and an institutional review board (IRB) approved all activities. On average, participants completed 9 out of 12 surveys $(S D=2.8)$, resulting in a $77 \%$ compliance rate typical of longitudinal diary studies (e.g., Bakker, Vergel, \& Kuntze, 2015; Totterdell, Wood \& Wall, 2006).

\section{Measures}

Physical Health outcomes

Two items were used to measures weekly sleep outcomes, adapted from the Pittsburgh Sleep Quality Index (PSQI; Buysse, Reynolds, Monk, Berman, \& Kupfer, 1989): sleep quality and sleep adequacy. Sleep quality, "How would you rate your sleep quality for the past 7 days overall?” was rated on a 4-point scale ranging from 1 (very bad) to 4 (very good). Sleep adequacy, "In the past 7 days/nights, how many nights/days have you received adequate sleep?" 
was rated on an 8-point scale ranging from 1 (0 days) to 8 (7 days). Other health items came from a health event checklist used by Carney, Armeli, Tennen, Affleck, and O’Neil (2000), including "How often have you experienced headaches in the past 7 days?," and "How often have you tried to eat healthy over the past 7 days?" Both the headache item and healthy-eating attempts item were rated on a 5-point scale from 1 (never) to 5 (very often). Single-items measures of health are considered to be reliable and valid (e.g., Andrews \& Withey 1976). Further, specific survey items that focus on discrete behaviors or experiences are likely more accurate than global assessments (see Reis, Gable, \& Maniaci, 2014). In addition, previous diary studies of similar health outcomes have employed single-item measures (e.g., Lee, Crain, McHale, Almeida, \& Buxton, 2017).

\section{Gratitude reception}

Reception of gratitude expressions was assessed using 5 items in which participants were asked how many shifts they were thanked by their patient, patient's family, charge nurse, physician, or coworker, during the past 7 days, with response options ranging from 0 ( 0 shifts $)$ to 6 (6 or more shifts). These items were created with the help of subject matter experts, and content analysis following focus groups with practicing nurses, which demonstrated the facevalidity, practical significance and importance of these items to the population of interest (Sinclair et al., 2015). The gratitude items were presented as an events checklist, and thus can be considered a formative measurement for which assessment of internal consistency is not meaningful (Diamantopolos \& Winklhofer, 2001). 
Satisfaction with quality care

The 3-item Satisfaction with Quality Care scale (SQC; Hinshaw \& Atwood, 1984) was adapted to measure nurses' positive evaluations with work-related tasks over the past 7 days. For example, participants were asked items including "The patient care I gave this week met my own standards of good patient care." Items were rated on a 5-point scale from 1 (strongly disagree) to 5 (strongly agree). The measure demonstrated good internal consistency across the 12 weeks $(\alpha$ range across the 12 weeks $=.92-.98$ ).

\section{Demographic and covariate information}

Demographic information, including age, gender, ethnicity, education, relationship status, and work variables were collected during Wave 1 of data collection prior to the weekly survey. In addition, we measured a set of covariates to allow for testing of alternate explanations for our results. When examining indirect effects, the direction of mediation models must be supported by theory and account for covarying variables that may contribute to outcomes in addition to meeting assumptions regarding measurement error (Judd \& Kenny, 2010). Therefore, number of shifts, night shift, and optimism were controlled for in all models. ${ }^{1}$ The number of work shifts was calculated for each week from nurse-reported shift time logs, and included as a withinperson control variable. Whether nurses completed at least one night shift that week (Yes/No) was also included as a within-person control. We included optimism as a between-persons covariate because, while a distinct construct, optimism may show a similar pattern to gratitude in terms of increasing a life orientation which subsequently relates to physical health (Carver, Scheier, \& Segerstrom, 2010; Wood et al., 2010). Optimism was measured at Wave 1 using 5 items adapted from the Life Orientation Test (Scheier, Carver, \& Bridges, 1994; $\alpha=.76$ ). 


\section{Data Analytic Strategy}

Preliminary analyses included descriptive statistics, bivariate correlations, and intraclass correlations. Due to the mixed-level nature of the over-time data, correlations were calculated between variables measured repeatedly over the study weeks $\left(\mathrm{r}_{\mathrm{ij}}\right)$ as well as between aggregated variables ( $\mathrm{r}_{\mathrm{j}}$; representing a nurse's average across weeks). Our primary data analytic approach was based on the 1-1-1 multilevel mediation model described by Krull and McKinnon (2001), in which the independent variable, mediator, and outcome are all time-varying. We examined indirect effects of gratitude reception on health via SQC. Thus, there were 4 models tested, one for each of the health outcomes, whereby gratitude reception was the independent variable and SQC was the mediator. Following expert recommendations (Preacher, Zyphur, \& Zhang, 2010; Preacher et al., 2011), multilevel mediation models were tested with fixed slopes using structural equation modelling (SEM) in Mplus (version 5.1; Muthén \& Muthén, 2008) which accounted for nesting of weeks within participants (see Figure 1). This approach accounts for potentially differing within-person (weekly-level) and between-person (individual-level) processes by estimating indirect effects for each level of the model. Within and between indirect effects were estimated using maximum likelihood estimation methods that are robust against missing data, nonindependence of observations, unbalanced clustering, and non-normality concerns.

\section{Results}

\section{Descriptive Statistics and Intracorrelations}

Descriptive information as well as bivariate and intraclass correlations are presented in Table 1. Bivariate correlations showed that gratitude reception was positively related to SQC scores at the weekly level $\left(r_{i j}=.15, p<.01\right)$; however, the aggregated correlation was not significant $\left(r_{j}=.13\right.$, $p=.12)$. SQC was significantly correlated with the sleep quality $\left(r_{j}=.24, p<.01\right)$, sleep 
adequacy $\left(r_{j}=.29, p<.01\right)$, headaches $\left(r_{j}=.20, p<.05\right)$, and healthy eating attempts $\left(r_{j}=.26, p\right.$ $<.01)$ at the aggregated level as well as the weekly level $\left(r_{i j}=.16, p<.01 ; r_{i j}=.17, p<.01 ; r_{i j}=\right.$ $-.15, p<.01 ; r_{i j}=.18, p<.01$, respectively). Gratitude reception did not have strong correlations with the physical health outcome variables at either the aggregate or weekly level (see Table 1).

\section{Hypothesis testing}

Multilevel mediation effects testing the hypothesized paths for all 4 models, predicting sleep quality, sleep adequacy, headaches and attempts to eat healthy are presented in Table 2. All models were just-identified; thus, fit indices are not reported.

[Include Table 1 near here]

\section{Sleep Quality}

Multilevel SEM analyses revealed that gratitude reception predicted SQC at the betweenperson level $\left(a_{j}=.23, p=.005\right)$, such that nurses who tended to report receiving more gratitude also reported higher levels of satisfaction with care, accounting for covariates. The betweenperson effects between SQC and sleep quality $\left(b_{j}=.14, p=.19\right)$ and between gratitude reception and sleep quality $\left(c_{j}=.06, p=.39\right)$ were not significant.

At the within-person level, gratitude reception predicted SQC $\left(a_{i j}=.09, p=.009\right)$. In turn, SQC predicted greater sleep quality $\left(b_{i j}=.08, p=.006\right)$ within week. Analyses revealed a significant indirect effect of gratitude reception predicting increased sleep quality $\left(a b_{\mathrm{ij}}=.01\right.$, $95 \%$ CI: $[.00, .01])^{2}$, indicating that when nurses received more thanks, they were more satisfied with the care they provide their patients, which in turn predicted better subjective sleep that week. However, gratitude reception did not directly predict sleep quality at the within-person level $\left(c_{i j}=.01, p=.63\right)$. 


\section{Sleep Adequacy}

At the individual (between-persons) level, gratitude reception predicted SQC across weeks $\left(a_{j}=.23, p=.005\right)$. In turn, SQC predicted sleep adequacy $\left(b_{j}=.54, p=.04\right)$, indicating that nurses who tended to be more satisfied across time reported more nights of adequate sleep on average. Gratitude reception did not predict sleep adequacy controlling for SQC at the between person level $\left(c_{j}=.13, p=.54\right)$. Further, a between-persons mediation effect did not emerge $\left(a_{j} b_{j}=.12,95 \%\right.$ CI: $\left.[-.01, .24]\right)$.

Within-person effects indicated that receiving gratitude predicted increased SQC $\left(a_{i j}=\right.$ $.09, p=.009)$, and SQC was associated with more reports of adequate night's sleep within a given week $\left(b_{i j}=.20, p=.019\right)$. Similar to reports for sleep quality, gratitude reception did not predict sleep adequacy directly $\left(c_{i j}=-.10, p=.17\right)$. Rather, being thanked more in a week predicted more adequate sleep nights that week as a function of greater satisfaction with quality care $\left(a_{i j} b_{i j}=.02,95 \% \mathrm{CI}:[.00, .03]\right)^{2}$.

\section{Headaches}

Gratitude reception predicted increased SQC at the aggregate level $\left(a_{j}=.23, p=.005\right)$. However, no other significant between-person effects between gratitude reception and headaches $\left(b_{j}=-.21, p=.09\right)$ or between SQC and headaches $\left(c_{j}=-.04, p=.73\right)$ emerged.

Following a similar pattern to sleep, receiving gratitude was associated with increased SQC scores $\left(a_{i j}=.09, p=.009\right)$ at the within-person level. SQC, in turn predicted decreased headaches within week $\left(b_{i j}=-.13, p=.004\right)$. While gratitude reception did not directly reduce headaches $\left(c_{i j}=.01, p=.84\right)$, there was a significant indirect effect via SQC $\left(a_{i j} b_{i j}=-.01,95 \%\right.$ CI: $[-.02, .00])^{2}$. 


\section{Healthy Eating Attempts}

Gratitude reception predicted increased SQC $\left(a_{j}=.23, p=.005\right)$, and SQC was associated with healthy eating attempts $\left(b_{j}=.39, p=.006\right)$ between-persons. Nurses who received more thanks reported being more satisfied over time, and nurses who were more satisfied on average tried to eat healthy. However, similar to the direct effect between gratitude reception and eating health $\left(c_{j}=-.10, p=.36\right)$, the indirect effect for healthy eating attempts was not significant $\left(a_{j} b_{j}\right.$ $=.09,95 \%$ CI: $[-.01, .18])$ between nurses.

Consistent with above within-person results, being thanked more on average within a week was associated with increased SQC scores $\left(a_{i j}=.09, p=.009\right)$. Further, SQC scores predicted attempting to eat healthy more often within a given week $\left(b_{i j}=.12, p=.001\right)$. Weekly gratitude reception did not uniquely predict healthy eating that same week $\left(c_{i j}=.03, p=.28\right)$. Yet, SQC mediated the relationship between receiving gratitude and trying to eat healthy $\left(a_{i j} b_{i j}=\right.$ $.01,95 \%$ CI: $[.00, .02])^{2}$.

[Include Table 2 near here]

\section{Discussion}

Consistent with literature on generalized gratitude experiences, this study found that receiving expressions of gratitude predicts better physical health via psychological well-being, specifically through work-related satisfaction. Receiving more thanks within a week was related to greater nurse satisfaction with the care they provided, and in turn better sleep quality, sleep adequacy, decreased headaches, and healthy eating intentions. In most cases, the mediation processes operated only within week, rather than at the individual-level. For example, gratitude reception was associated with satisfaction with care at the between-persons level, indicating that nurses 
who received more thanks on average reported experiencing higher levels of satisfaction with care compared to nurses who received less gratitude on average.

However, satisfaction with care and gratitude reception did not consistently predict health outcomes at the individual level. While this finding may be surprising given research examining the relation between individual-level (i.e., trait or generalized) gratitude and psychological wellbeing (e.g., Wood et al., 2010) and the mediation of individual-level gratitude and health via psychological resources (e.g., O’Connell et al., 2016; Wood et al., 2009), the process of receiving rather than experiencing gratitude may be context-dependent. For example, the effects of receiving gratitude and feeling satisfied with one's work may be due to work-related experiences or conditions that nurses encounter week-to-week and may not manifest at the personal level. In other words, the in-vivo interactions with patients, families, and coworkers that contribute to a particularly satisfying experience may be more beneficial to one's physical health than the accumulation of "thank you's" or satisfying experiences over time. Finally, multilevel mediation results indicated that weekly gratitude was not directly related to any of the health outcomes. This is consistent with our argument that received gratitude has an indirect relationship with physical health and extends previous literature concerning the indirect effects of affect on physical health (e.g., DeSteno et al., 2013).

Consistent with COR Theory (Hobfoll, 1989; 2001) our work highlights the health benefits of receiving thanks, particularly for those in helping jobs, such as nursing. When nurses are thanked for their care, they may feel more satisfied with the care they provided, and thus experience better physical health. This is also supported by broaden-and-build theory (Fredrickson 2001; 2004); increases in gratitude emotion expressions may increase nurses' positive resources resulting in higher satisfaction with patient care that they provide and potential 
health benefits. Thus, being thanked seems to be a source of positive feedback or recognition about nurses' performance that leads to individual psychological and physical well-being outcomes.

Our findings underscore the importance of examining expressions of gratitude and their relative impact on the benefactor of care provisions. This work extends literature demonstrating the positive outcomes of expressed gratitude. One's 'thank you's do not go unnoticed, nor do they lack consequences for individual well-being and physical health. This study may inform health-care organizations interested in implementing programs to improve the well-being of nurses. For example, organizations should consider policies that promote increased appreciation for nursing care in addition to initiatives aimed at creating a culture of interpersonal gratitude for health-care professionals' hard work. This is supported by research indicating that gratitude and support for health-care professions promotes a better organizational climate (Bennet, Ross, \& Sunderland, 1996), reduces burnout symptoms (Converso et al., 2015), and improves physical health (Pisanti, van der Doef, Maes, Lazzari, Bertini, 2011).

\section{Limitations and future directions}

Our study has many strengths, most notably the weekly surveys enabling us to examine the relationships of interest both within- and between-persons. However, we also note some important limitations that should be addressed in future research. First, our health outcome variables were assessed using single-item measures. Though multi-item assessments are typically preferred, single-item measures for physical health have been shown to perform comparably well as multi-item scales and tend to indicate predictive validity for mortality and undiagnosed diseases (see McDowell, 2006). Furthermore, single-item measures have the advantage of being 
face valid and brief to administer, which is helpful for reducing participant fatigue (e.g., Larsen \& Fredrickson, 1999) in intensive longitudinal studies such as weekly surveys.

Second, this study cannot account for causal relationships between gratitude reception, satisfaction with care, and physical health. While other studies have examined the temporal precedence between trait gratitude and psychology well-being (e.g., Wood et al., 2008) as well as subjective well-being and health (Feist, Bodner, Jacobs, Miles, \& Tan, 1995), we based our hypotheses on theory and empirical evidence suggesting the current directional model within the context of nursing.

Our sample was comprised of experienced nurses in their mid-forties, on average, which may not generalize to the experience of younger, less-experienced nurses. However, our findings were not attenuated when age was included in the models. It is noteworthy that receiving gratitude in an older, more experienced sample of nurses indirectly predicted physical health, given that older nurses may experience a greater degree of strain over the years compared to younger, less-experienced counterparts. Future work should examine differences in gratitude in nurses across a wider range of age and experience. Furthermore, this work could be extended to occupations beyond health-care, including other helping professions such as civil servants or military personnel.

Moreover, the present study was limited in the variety of mechanisms through which gratitude may predict physical health. This study examined a work-relevant measure of satisfaction; however, satisfaction with life, or positive and negative affect, for examples, could be additional intraindividual mechanisms of received gratitude expression and physical health. Furthermore, strong evidence supports the social function of gratitude expressions (e.g., Wood et al., 2010); gratitude expressions can help people find new high-quality relationships as well as 
strengthen and maintain one's current close relationships, most likely through perceived responsiveness (Algoe, 2012). Future studies should extend this work to relationships in healthcare (e.g., Reis et al., 2008).

\section{Conclusion}

This study extends gratitude literature by examining how expressions of gratitude contribute to physical well-being for support providers, in this case, nurses- an occupation that is characterized by the provision of caring behaviors as well as its demanding work conditions. Results indicated that receiving thanks at work was indirectly associated with better subjective physical health via satisfaction with patient care within-week. Our findings indicate that receiving expressions of gratitude may increase individual physical health through building psychological resources. Gratitude interventions, particularly those interested in organizational outcomes, may consider the impact of acknowledging gratitude towards care providers. 


\section{Acknowledgements}

The authors acknowledge with gratitude Sheila Umemoto for her thoughtful support.

\section{Disclosure Statement}

No potential conflict of interest was reported by the authors.

\section{Footnotes}

${ }^{1}$ Age, gender, occupational tenure, self-efficacy, and neuroticism were also tested as covariates.

However, these variables did not emerge as significant predictors of physical health outcomes or satisfaction with care, and thus, were removed from the final analyses.

${ }^{2}$ The ". 00 " value within the $95 \%$ confidence interval is due to decimal point rounding within the Mplus software; outputs report the indirect effect as p-value $<.05$. 


\section{References}

Adriaenssens, J., De Gucht, V., Van Der Doef, M., \& Maes, S. (2011). Exploring the burden of emergency care: Predictors of stress-health outcomes in emergency nurses. Journal of Advanced Nursing, 67(6), 1317-1328.

Aiken L.H., Sermeus W., Van den Heede K., Sloane D.M., Busse R., McKee M., ... Kutney-Lee A. (2012). Patient safety, satisfaction and quality of hospital care: cross sectional surveys of nurses and patients in 12 countries in Europe and the United States. BMJ, 344, e1717.

Algoe, S. B. (2012). Find, remind, and bind: The functions of gratitude in everyday relationships. Social and Personality Psychology Compass, 6, 455-469.

Algoe, S. B., \& Stanton, A. L. (2012). Gratitude when it is needed most: Social functions of gratitude in women with metastatic breast cancer. Emotion, 12(1), 163-168.

Algoe, S. B., \& Zhaoyang, R. (2016). Positive psychology in context: Effects of expressing gratitude in ongoing relationships depend on perceptions of enactor responsiveness. The journal of positive psychology, 11(4), 399-415.

Algoe, S. B., Fredrickson, B. L., \& Gable, S. L. (2013). The social functions of the emotion of gratitude via expression. Emotion, 13, 605-609.

Algoe, S., Kurtz, S., \& Hilaire, L. (n.d.). (2016). Putting the "You" in "Thank You": Examining Other-Praising Behavior as the Active Relational Ingredient in Expressed Gratitude. Social Psychological \& Personality Science, 7(7), 658-666.

Andrews, F., \& Withey, S. B. (1976). Social indicators of well-being: Americans' perceptions of life quality. New York: Plenum Press.

Bakker, A. B., Vergel, A. I. S., \& Kuntze, J. (2015). Student engagement and performance: A weekly diary study on the role of openness. Motivation and Emotion, 39(1), 49-62.

Bennett, L., Ross, M. W., \& Sunderland, R. (1996). The relationship between recognition, rewards and burnout in AIDS caring. Aids care, 8(2), 145-154.

Buysse, D. J., Reynolds III, C. F., Monk, T. H., Berman, S. R., \& Kupfer, D. J. (1989). The Pittsburgh Sleep Quality Index: a new instrument for psychiatric practice and research. Psychiatry research, 28(2), 193-213. 
Carney, M. A., Armeli, S., Tennen, H., Affleck, G., \& O'neil, T. P. (2000). Positive and negative daily events, perceived stress, and alcohol use: A diary study. Journal of Consulting and Clinical Psychology, 68(5), 788-798.

Carver, C. S., Scheier, M. F., \& Segerstrom, S. (2010). Optimism. Clinical Psychology Review, $30,879-889$.

Converso, D., Loera, B., Viotti, S., \& Martini, M. (2015). Do positive relations with patients play a protective role for healthcare employees? Effects of patients' gratitude and support on nurses' burnout. Frontiers in psychology, 6, 1-11.

DeSteno, D., Gross, J. J., \& Kubzansky, L. (2013). Affective science and health: The importance of emotion and emotion regulation. Health Psychology, 32(5), 474-486.

Diamantopoulos, A., \& Winklhofer, H. M. (2001). Index construction with formative indicators: An alternative to scale development. Journal of Marketing Research, 38, 269-277.

Eley, D., Eley, R., Bertello, M., \& Rogers-Clark, C. (2012). Why did I become a nurse? Personality traits and reasons for entering nursing. Journal of advanced nursing, 68(7), 1546-1555.

Emmons R.A. \& McCullough M.E. (2003) Counting blessings versus burdens: an experimental investigation of gratitude and subjective well-being in daily life. Journal of Personality and Social Psychology, 84 (2), 377-389.

Emmons, R. A., McCullough, M. E., \& Tsang, J.-A. (2003). The assessment of gratitude. In S. J. Lopez \& C. R. Snyder (Eds.), Positive psychological assessment: A handbook of models and measures (pp. 327-341). Washington, DC, US: American Psychological Association.

Faragher, E., Cass, M., \& Cooper, C. (2005). The Relationship between Job Satisfaction and Health: A Meta-Analysis. Occupational and Environmental Medicine, 62(2), 105-112.

Feist, G. J., Bodner, T. E., Jacobs, J. F., Miles, M., \& Tan, V. (1995). Integrating top-down and bottom-up structural models of subjective well-being: A longitudinal investigation. Journal of Personality and Social Psychology, 68, 138-150.

Fredrickson, B. L. (2001). The role of positive emotions in positive psychology: The broadenand-build theory of positive emotions. American Psychologist, 56, 218 -226.

Fredrickson, B. L. (2004). Gratitude, like other positive emotions, broadens and builds. In Emmons, R. \& McCullough M. (Eds.), The psychology of gratitude (145-166). New York: Oxford University Press. 
Grant, A. M., \& Gino, F. (2010). A little thanks goes a long way: Explaining why gratitude expressions motivate prosocial behavior. Journal of personality and social psychology, 98(6), 946-955.

Hasson, D., \& Gustavsson, P. (2010). Declining sleep quality among nurses: a population-based four-year longitudinal study on the transition from nursing education to working life. PloS one, 5(12), e14265.

Hill, P.L. Allemand, M. \& Roberts, B. W. (2013). Examining the pathways between gratitude and self-rated physical health across adulthood. Personality and Individual Differences, 54(1), 92-96.

Hinshaw A.S., \& Atwood J.R. (1984). Nursing Staff Turnover, Stress, and Satisfaction: Models, Measures, and Management. In: Werley H.H., Fitzpatrick J.J. (eds) Annual Review of Nursing Research (pp. 133 - 153). Berlin, Heidelberg: Springer.

Hobfoll, S. (1989). Conservation of resources: A new attempt at conceptualizing stress. American Psychologist, 44, 513-524.

Hobfoll, S. (2001). The influence of culture, community, and the nested-self in the stress process: Advancing conservation of resources theory. Applied Psychology: An International Review, 50, 337-369.

Jackowska, M., Brown, J., Ronaldson, A., \& Steptoe, A. (2015). The impact of a brief gratitude intervention on subjective well-being, biology and sleep. Journal of Health Psychology, 21(10), 2207-2217.

Judd, C. M., \& Kenny, D. A. (2010). Data analysis in social psychology: Recent and recurring issues. In S.T. Fiske, D.T. Gilbert, \& G. Lindzey (Eds.), Handbook of social psychology, (pp. 115-142). Hoboken, NJ: John Wiley \& Sons, Inc.

Krull, J. L., \& MacKinnon, D. P. (2001). Multilevel modeling of individual and group level mediated effects. Multivariate behavioral research, 36(2), 249-277.

Lambert, N. M., Graham, S. M., \& Fincham, F. D. (2009). A prototype analysis of gratitude: Varieties of gratitude experiences. Personality and Social Psychology Bulletin, 35(9), 1193-1207.

Lambert, N. M., Fincham, F. D., Stillman, T. F., \& Dean, L. R. (2009). More gratitude, less materialism: The mediating role of life satisfaction. The Journal of Positive Psychology, $4(1), 32-42$. 
Larsen, R.J., \& Fredrickson, B.L. (1999). Measurement issues in emotion research. In D. Kahneman, E. Diener,\& N. Schwarz (Eds.), Well-being: The foundations of hedonic psychology (p. 40-60). New York: Russell Sage Foundation.

Lee, S., Crain, T. L., McHale, S. M., Almeida, D. M., \& Buxton, O. M. (2017). Daily antecedents and consequences of nightly sleep. Journal of sleep research, 26(4), 498509.

Lin, K. C., Huang, C. C., \& Wu, C. C. (2007). Association between stress at work and primary headache among nursing staff in Taiwan. Headache: The Journal of Head and Face Pain, 47(4), 576-584.

Lockley, S. W., Barger, L. K., Ayas, N. T., Rothschild, J. M., Czeisler, C. A., \& Landrigan, C. P. (2007). Effects of health care provider work hours and sleep deprivation on safety and performance. The Joint Commission Journal on Quality and Patient Safety, 33, 7-18.

Lyubomirsky, S., Dickerhoof, R., Boehm, J. K., \& Sheldon, K. M. (2011). Becoming happier takes both a will and a proper way: An experimental longitudinal intervention to boost well-being. Emotion, 11(2), 391-402.

McCullough, M. E., Kimeldorf, M. B., \& Cohen, A. D. (2008). An adaptation for altruism? The social causes, social effects, and social evolution of gratitude. Current Directions in Psychological Science, 17(4), 281-285.

McDowell, I. (2006). Measuring health: A guide to rating scales and questionnaires (Third ed.). Oxford: Oxford University Press.

Meier, L. L., Tschudi, P., Meier, C. A., Dvorak, C., \& Zeller, A. (2015). When general practitioners don't feel appreciated by their patients: prospective effects on well-being and work-family conflict in a Swiss Longitudinal Study. Family practice, 32(2), 181186.

Morrison, K. B., \& Korol, S. A. (2014). Nurses' perceived and actual caregiving roles: identifying factors that can contribute to job satisfaction. Journal of clinical nursing, 23(23-24), 3468-3477.

Muthén, L. K., \& Muthén, B. O. (2008). Mplus (Version 5.1). Los Angeles, CA: Muthén \& Muthén.

O’Connell, B.H., O’Shea, D., \& Gallagher, S. (2016). Mediating effects of loneliness on the gratitude-health link. Personality and Individual Differences, 98, 179-183. 
Perry, B. (2005). Core nursing values brought to life through stories. Nursing Standard (through 2013), 20(7), 41-48.

Pisanti, R., van der Doef, M., Maes, S., Lazzari, D., \& Bertini, M. (2011). Job characteristics, organizational conditions, and distress/well-being among Italian and Dutch nurses: a cross-national comparison. International Journal of Nursing Studies, 48(7), 829-837.

Preacher, K. J., Zhang, Z., \& Zyphur, M. J. (2011). Alternative methods for assessing mediation in multilevel data: The advantages of multilevel SEM. Structural Equation Modeling, 18(2), 161-182.

Preacher, K. J., Zyphur, M. J., \& Zhang, Z. (2010). A general multilevel SEM framework for assessing multilevel mediation. Psychological methods, 15(3), 209-233.

Reis, H. T., Clark, M. S., Pereira Gray, D. J., Tsai, F. F., Brown, J. B., Stewart, M., \& Underwood, L. G. (2008). Measuring responsiveness in the therapeutic relationship: A patient perspective. Basic and Applied Social Psychology, 30(4), 339-348.

Reis H., Gable, S., \& Maniaci, M. (2014). Methods for studying everyday experience in its natural context. In Reis, H., \& Judd, C. M. (Eds.), Handbook of research methods in social and personality psychology (pp. 373-403). New York, NY: Cambridge University Press.

Scheier, M. F., Carver, C. S., \& Bridges, M. W. (1994). Distinguishing optimism from neuroticism (and trait anxiety, self-mastery, and self-esteem): a reevaluation of the Life Orientation Test. Journal of personality and social psychology, 67(6), 1063-1078.

Sinclair, R. R., Mohr, C. D., Davidson, S., Sears, L. E., Deese, M. N., Wright, R. R., Waitsman, M., Jacobs, L., Cadiz, D. (2009). The Oregon Nurse Retention Project - Final Report to the Northwest Health Foundation. Portland, OR: Northwest Health Foundation.

Sinclair, R. R., Sliter, M., Mohr, C. D., Sears, L. E., Deese, M. N., Wright, R. R., ... \& Jacobs, L. (2015). Bad versus good, what matters more on the treatment floor? Relationships of positive and negative events with nurses' burnout and engagement. Research in nursing \& health, 38(6), 475-491.

Totterdell, P., Wood, S., \& Wall, T. (2006). An intra-individual test of the demands-control model: A weekly diary study of psychological strain in portfolio workers. Journal of Occupational and Organizational Psychology, 79(1), 63-84. 
Tucker, S. J., Harris, M. R., Pipe, T. B., \& Stevens, S. R. (2010). Nurses' ratings of their health and professional work environments. AAOHN journal, 58(6), 253-267.

U.S. Department of Labor, Bureau of Labor Statistics. (2018). Occupational Outlook Handbook. Washington, D.C.: GPO, U.S. Bureau of Labor Statistics. Retrieved from http://www.bls.gov/ooh/healthcare/registered-nurses.htm

Winwood, P. C., \& Lushington, K. (2006). Disentangling the effects of psychological and physical work demands on sleep, recovery and maladaptive chronic stress outcomes within a large sample of Australian nurses. Journal of advanced nursing, 56(6), 679-689.

Wood, A. M., Froh, J. J., \& Geraghty, A. W. (2010). Gratitude and well-being: A review and theoretical integration. Clinical psychology review, 30(7), 890-905.

Wood, A. M., Joseph, S., Lloyd, J., \& Atkins, S. (2009). Gratitude influences sleep through the mechanism of pre-sleep cognitions. Journal of Psychosomatic Research, 66(1), 43-48.

Wood, A. M., Maltby, J., Gillett, R., Linley, P. A., \& Joseph, S. (2008). The role of gratitude in the development of social support, stress, and depression: Two longitudinal studies. Journal of Research in Personality, 42(4), 854-871.

You, L. M., Aiken, L. H., Sloane, D. M., Liu, K., He, G. P., Hu, Y., ... \& Shang, S. M. (2013). Hospital nursing, care quality, and patient satisfaction: cross-sectional surveys of nurses and patients in hospitals in China and Europe. International journal of nursing studies, 50(2), 154-161. 
Table 1. Descriptive statistics, intraclass correlations, and bivariate aggregated and weekly correlations

\begin{tabular}{|c|c|c|c|c|c|c|c|c|c|c|c|}
\hline & $M$ & $S D$ & $I C C$ & 2 & 3 & 4 & 5 & 6 & 7 & 8 & 9 \\
\hline \multicolumn{12}{|l|}{ Wave 1 Measure } \\
\hline 1. Optimism & 3.75 & .58 & --- & .10 & $.28^{* *}$ & $.27^{* *}$ & $.19^{*}$ & $-.19^{*}$ & .13 & .02 & -.14 \\
\hline \multicolumn{12}{|l|}{ Weekly Measures } \\
\hline 2. Gratitude Reception & 1.38 & .92 & .48 & --- & .13 & .11 & .09 & .01 & .06 & $.26^{* *}$ & $-.22^{* *}$ \\
\hline 3. SQC & 4.08 & .76 & .56 & $.15^{* *}$ & --- & $.24^{* *}$ & $.29^{* *}$ & $-.20^{*}$ & $.26^{* *}$ & -.03 & -.01 \\
\hline 4. Sleep Quality & 2.90 & .67 & .45 & $.08^{* *}$ & $.16^{* *}$ & --- & $.85^{* *}$ & $-.38^{* *}$ & .10 & -.08 & -.06 \\
\hline 5. Sleep Adequacy & 4.67 & 1.80 & .55 & .05 & $.17^{* *}$ & $.73^{* *}$ & --- & $-.36^{* *}$ & .12 & -.05 & -.03 \\
\hline 6. Headaches & 2.15 & 1.13 & .53 & -.01 & $-.15^{* *}$ & $-.27^{* *}$ & $-.26^{* *}$ & --- & -.06 & $.22^{* *}$ & -.05 \\
\hline 7. Tried to Eat Healthy & 3.79 & 1.00 & .67 & .04 & $.18^{* *}$ & $.08^{*}$ & $.07^{*}$ & -.04 & -- & -.03 & $-.20^{*}$ \\
\hline 8. Number of Shifts & 2.42 & 1.77 & .25 & $.45^{* *}$ & -.04 & -.02 & $-.08^{* *}$ & $.08^{* *}$ & .05 & --- & -.16 \\
\hline 9. Night Shift & .39 & .49 & .73 & $-.12^{* *}$ & -.01 & $-.11^{* *}$ & $-.11^{* *}$ & -.02 & $-.15^{* *}$ & -.03 & --- \\
\hline
\end{tabular}

Note. Above the diagonal, correlations are between aggregated variables ( $r$; nurses' average across weeks; $N=146$ ); below the

diagonal, correlations are between weekly variables $\left(r_{i j} ; N=1752\right) . M=$ mean; $S D=$ standard deviation; $I C C=$ intraclass correlation;

$\mathrm{SQC}=$ satisfaction with quality care. ${ }^{*} p<.05,{ }^{*} p<.01$. 
Table 2. Multilevel mediation models predicting sleep quality, sleep adequacy, headaches, and eating healthy.

\begin{tabular}{|c|c|c|c|c|c|c|c|c|}
\hline \multirow[b]{2}{*}{ Parameter } & \multicolumn{2}{|c|}{ Sleep quality } & \multicolumn{2}{|c|}{ Sleep Adequacy } & \multicolumn{2}{|c|}{ Headaches } & \multicolumn{2}{|c|}{ Eating healthy } \\
\hline & Estimate & SE & Estimate & SE & Estimate & SE & Estimate & SE \\
\hline \multicolumn{9}{|l|}{ Between level } \\
\hline Intercept & $1.79^{* * * *}$ & .43 & 1.64 & 1.13 & $3.21^{* * * *}$ & .68 & $2.37^{* *}$ & .70 \\
\hline $\mathrm{GR} \rightarrow \mathrm{SQC}\left(\mathrm{a}_{\mathrm{j}}\right)$ & $.23^{* *}$ & .08 & $.23^{* *}$ & .08 & $.23^{* *}$ & .08 & $.23^{* *}$ & .08 \\
\hline $\mathrm{SQC} \rightarrow \mathrm{PHO}\left(\mathrm{b}_{\mathrm{j}}\right)$ & .14 & .10 & $.54^{*}$ & .26 & $-.21^{+}$ & .12 & $.39^{* *}$ & .14 \\
\hline $\mathrm{GR} \rightarrow \mathrm{PHO}\left(\mathrm{c}_{\mathrm{j}}\right)$ & .06 & .07 & .13 & .21 & -.04 & .12 & -.10 & .11 \\
\hline Indirect effect & .03 & .02 & $.12^{+}$ & .07 & -.05 & .03 & $.09^{+}$ & .05 \\
\hline Residual variance outcome & $.18^{* * *}$ & .03 & $1.57^{* * * *}$ & .22 & $.58^{* * *}$ & .08 & $.58^{* * *}$ & .07 \\
\hline Residual variance SQC & $.29^{* * *}$ & .05 & $.29^{* * * *}$ & .05 & $.29^{* * *}$ & .05 & $.29^{* * *}$ & .05 \\
\hline \multicolumn{9}{|l|}{ Within level } \\
\hline $\mathrm{GR} \rightarrow \mathrm{SQC}\left(\mathrm{a}_{\mathrm{ij}}\right)$ & $.09^{* *}$ & .03 & $.09^{* *}$ & .03 & $.09^{* *}$ & .03 & $.09^{* *}$ & .03 \\
\hline $\mathrm{SQC} \rightarrow \mathrm{PHO}\left(\mathrm{b}_{\mathrm{ij}}\right)$ & $.08^{* *}$ & .03 & $.20^{*}$ & .08 & $-.13^{* *}$ & .05 & $.12^{* *}$ & .04 \\
\hline $\mathrm{GR} \rightarrow \mathrm{PHO}\left(\mathrm{c}_{\mathrm{ij}}\right)$ & .01 & .03 & -.10 & .07 & .01 & .05 & .03 & .03 \\
\hline Indirect effect & $.01^{*}$ & .00 & $.02^{*}$ & .01 & $-.01^{*}$ & .01 & $.01^{*}$ & .01 \\
\hline Residual variance outcome & $.25^{* * *}$ & .02 & $1.50^{* * * *}$ & .09 & $.63^{* * *}$ & .04 & $.32^{* * *}$ & .04 \\
\hline Residual variance SQC & $.27^{* * * *}$ & .03 & $.27^{* * * *}$ & .03 & $.27^{* * * *}$ & .03 & $.27^{* * *}$ & .03 \\
\hline
\end{tabular}

Note. All models controlled for number of shifts worked within week, night shift, and optimism. The a, b, and c paths refer to Figure

1. GR = gratitude reception; $\mathrm{SQC}=$ satisfaction with care; $\mathrm{PHO}=$ physical health outcome (specified in column headings). ${ }^{+} p<.10$,

$* p<.05, * * p<.01, * * * p<.001$ 


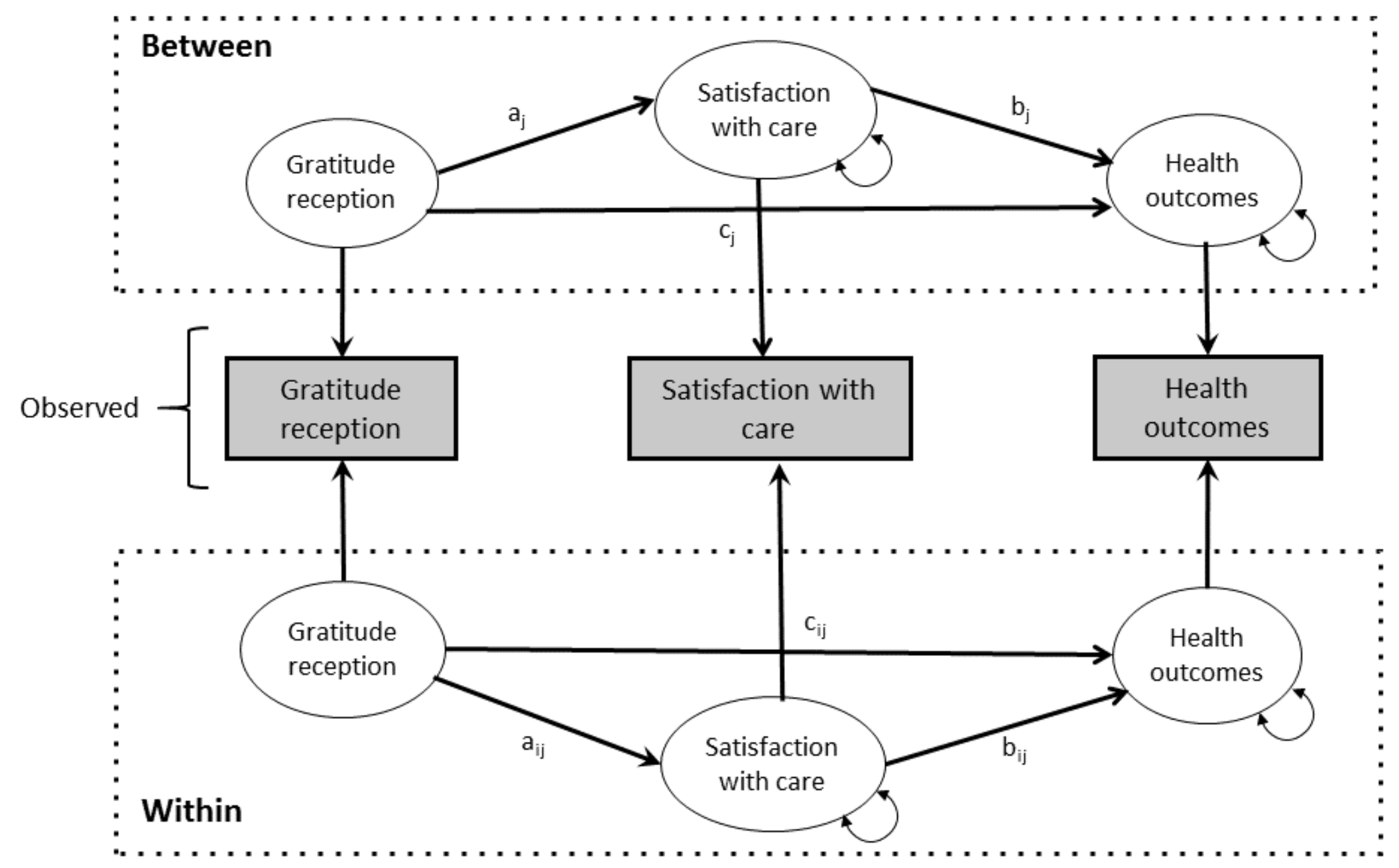

Figure 1 


\section{Figure Captions}

Figure 1. Multilevel structural equation model with fixed slopes predicting physical health outcomes (sleep quality, sleep adequacy, headaches, and trying to eat healthy) in separate models. 